\title{
Dimensions of early speech sound disorders: A factor analytic study
}

\author{
Barbara A. Lewis ${ }^{\text {a,* }}$, Lisa A. Freebairn ${ }^{\text {a }}$, Amy J. Hansen ${ }^{\text {a }}$, \\ Catherine M. Stein ${ }^{b}$, Lawrence D. Shriberg ${ }^{c}$, \\ Sudha K. Iyengar ${ }^{b, d}, H$. Gerry Taylor ${ }^{a}$ \\ ${ }^{a}$ Department of Pediatrics, Rainbow Babies and Childrens Hospital, \\ Behavioral Pediatrics and Psychology 6038, Case Western Reserve University, \\ 11100 Euclid Avenue, Cleveland, $\mathrm{OH}$ 44106-6038, United States \\ ${ }^{\mathrm{b}}$ Department of Epidemiology and Biostatistics, School of Medicine, \\ Case Western Reserve University, Cleveland, OH, United States \\ ${ }^{\mathrm{c}}$ University of Wisconsin-Madison, Madison, United States \\ ${ }^{\mathrm{d}}$ Department of Ophthalmology, School of Medicine, Case Western Reserve University, \\ Cleveland, $\mathrm{OH}$, United States
}

Received 24 March 2005; received in revised form 1 October 2005; accepted 10 November 2005

\begin{abstract}
The goal of this study was to classify children with speech sound disorders (SSD) empirically, using factor analytic techniques. Participants were 3-7-year olds enrolled in speech/language therapy $(N=185)$. Factor analysis of an extensive battery of speech and language measures provided support for two distinct factors, representing the skill dimensions of articulation/phonology and semantic/ syntactic skills. To validate these factors, 38 of the children were followed to school age to re-evaluate speech and language skills and assess reading/spelling achievement. The validity of the two factors was supported by their differential associations with school-age reading and spelling achievement, persistence of SSD, and affection status in family members. A closer relationship of the family member to the proband and male gender predicted higher odds of a disorder. The findings suggest that articulation/phonology and language abilities are at least partially independent in children with SSD and that these constructs have distinct clinical and biological correlates.
\end{abstract}

* Corresponding author. Tel.: +1 216844 6204; fax: +1 2168446276 .

E-mail address: bxl@po.cwru.edu (B.A. Lewis). 
Learning outcomes: The reader will develop knowledge about subtypes of speech sound disorders, understand the relationship between early speech sound disorders and later reading and spelling difficulties, and obtain information concerning familial transmission of speech sound disorders.

(C) 2005 Elsevier Inc. All rights reserved.

\section{Introduction}

\subsection{Subtype classifications}

Children with early speech sound disorders (SSD) of unknown etiology comprise the largest group of children referred for speech and language therapy, with an estimated prevalence of approximately $15 \%$ of children at 3 years of age (Shriberg, 2002). It is likely that these children represent a heterogeneous group, even when excluding children with conditions such as pervasive developmental delay, craniofacial dysmorphologies, and other neurodevelopmental disorders. Several schemas to classify subtypes of SSD have been proposed based on clinical observations, patterns of speech sound errors, and etiological factors.

One clinically useful method to subtype children with SSD is to group them according to whether or not the SSD is accompanied by additional language impairment (LI). Shriberg, Tomblin, and McSweeny (1998) report 11-15\% co-morbidity of speech delay with LI at 6 years of age, with considerably higher co-morbidity rates estimated for preschool children with speech delay (40-60\%; Shriberg \& Kwiatkowski, 1994). Numerous studies have validated the utility of this dichotomy by demonstrating poorer outcomes for children with combined SSD and LI than for children with isolated SSD (Aram \& Hall, 1989; Bishop \& Adams, 1990; Felsenfeld, McGue, \& Broen, 1995; Hall \& Tomblin, 1978; Lewis, Freebairn, \& Taylor, 2000; Menyuk et al., 1991; Nathan, Stackhouse, Goulandris, \& Snowling, 2004; Shriberg \& Austin, 1998). Young et al. (2002) followed a cohort at 19 years of age that was first assessed by Stothard, Snowling, Bishop, Chipchase, and Kaplan (1998). At the later follow-up, few differences were found in comparing the individuals with isolated SSD with controls, whereas the individuals whose SSD was co-morbid with LI lagged behind controls in all areas of academic achievement.

In our own studies, children with SSD accompanied by LI performed more poorly than children with isolated SSD at school age on measures of spelling, reading decoding, reading comprehension, and written language, as well as on language measures and phonological awareness (Lewis et al., 2000; Lewis, Freebairn, \& Taylor, 2002; Lewis, O'Donnell, Freebairn, \& Taylor, 1998). For example, 18\% of our cohort of children with an isolated SSD had reading problems in mid-elementary school, compared with $75 \%$ of those with combined SSD and LI (Lewis et al., 2000). The two groups did not differ in articulation, whether assessed at early childhood or at the later follow-up. Despite the generally better outcomes for children with isolated SSD, even this subgroup had deficiencies in spelling and reading decoding relative to normative expectations (Lewis et al., 2002; Young et al., 2002). These results suggest that the speech sound deficits of children with isolated SSD may themselves lead to later learning impairments. 
Another classification system was proposed by Dodd (1995). This system classifies SSD into five subtypes including articulation disorder, delayed phonological acquisition, consistent deviant disorder, inconsistent deviant disorder, and other (including dysfluency, dysarthria, and apraxia of speech). Dodd's system is based on the types of speech sound errors observed rather than the hypothesized etiological basis. Distinctions are made between delayed and deviant development, articulation and phonological errors, and the consistency of the speech sound errors. The "other" category is heterogeneous, both in the types of speech errors and the presumed underlying basis for the errors. Dodd (1995) has demonstrated the prognostic utility of these subtypes in studies showing different written language outcomes for children with speech sound delay than for children with deviant speech sound errors.

A framework for subtyping children with SSD has also been proposed by Shriberg and colleagues (Shriberg, 1993; Shriberg, Austin, Lewis, McSweeny, \& Wilson, 1997; Shriberg \& Kwiatkowski, 1982, 1994; Shriberg et al., 2005). Based on a complex disorder framework, this classification system proposes seven subtypes of SSD: speech delay-genetic, speech delay-otitis media with effusion, speech delay-apraxia, speech delay-dysarthria, speech delay-developmental psychosocial involvement, and two categories of speech errors limited to distortions of speech sounds. LI may be co-morbid with any of these categories, but is not considered in defining any of the subtypes. This classification system does not distinguish between "articulatory" versus "phonologically-based" errors. Emerging studies have provided support for diagnostic markers to differentiate among the seven proposed subtypes, but differential long-term outcomes for these subtypes have not been reported.

\subsection{Theoretical bases for subtyping of SSD}

Models of speech and language production (Caplan, 1992, 1994; Carrow-Woolfolk \& Lynch, 1982; Catts \& Kamhi, 1986; Gathercole \& Baddeley, 1989; Kandel, Schwartz, \& Jessel, 1991) suggest that speech sound production and spoken and written language rely on both shared and unshared processes. According to these models, the analyses of speech and spoken and written language rely on shared phonological representations for conversion of phonetic speech units or written graphemes to phonemes. Phonological memory and phonological awareness are key processes in these conversions. Meaning is attached to the utterance or text through shared semantic and morphologic/syntactic representations. However, speech production and written language are also modality specific. These systems involve the selection and retrieval of a template for the intended word, assembly and the sequencing of phonetic units or graphemes and the execution of the motor program. A disruption in a shared process, such as phonological memory, for example, would have adverse consequences for speech production as well as spoken and written language output. In contrast, a factor that impairs the output stage of articulatory planning would have more isolated effects on speech production. Thus, clinical subtypes of SSD alone or SSD with LI may have different underlying etiologies. A child with a SSD alone may have a disruption in a process unique to speech sound production, while a child with SSD and LI may have a disruption in a shared processing component. These theoretical underpinnings for SSD, LI, and RD are supported by recent genetic findings. 


\subsection{Genetic support for the subtyping of SSD}

Recent studies have supported the notion that some genetic factors impact shared processes while others influence unshared processes for SSD, LI, and RD. Early evidence came from the co-aggregation of SSD and LI within families (Felsenfeld et al., 1995; Gopnik \& Crago, 1991; Lahey \& Edwards, 1995; Lewis, 1992; Neils \& Aram, 1986; Rice, Haney, \& Wexler, 1998; Shriberg \& Kwiatkowski, 1994; Spitz, Tallal, Flax, \& Benasich, 1997; Tallal, Ross, \& Curtiss, 1989; Tomblin, 1989). According to these studies, 23-56\% of first degree family members of individuals with speech/language disorders are affected with one or both disorders. Studies that have examined family histories of reading disorders reveal a similarly high prevalence of reading problems in families with histories of SSD and/or LI (Lewis \& Freebairn, 1998).

Findings from twin, adoption, and genetic linkage studies provide further support for shared genetic influences on SSD, LI, and reading disorders (Bishop, North, \& Donlan, 1995; Felsenfeld \& Plomin, 1997; Lewis \& Thompson, 1992; Stein et al., 2004; Tomblin \& Buckwalter, 1998). In a recent study, Stein et al. (2004) examined a region on chromosome 3 that was previously associated with RD. They demonstrated that domains, such as phonological memory, common to SSD and RD are pleiotropically influenced by a quantitative trait locus on chromosome 3. A second study by Smith, Pennington, Boada, and Shriberg (2005) examined 111 probands with SSD and their 76 siblings. Smith et al. hypothesized that there is symptom, cognitive, and etiological overlap between SSD and RD. They found that the Goldman-Fristoe Test of Articulation (GFTA) linked significantly to a region on chromosomes 6 and 15, that were previously associated with RD. Although the possibility of separate genes for SSD and RD in these regions cannot be ruled out, it is more likely that RD and SSD share genes in these regions that may influence neurological functions. Plomin and Kovas (2005) have referred to genes with broad rather than specific effects as generalist genes and have proposed that such genes contribute to multiple forms of learning disabilities.

Alternatively, some genes may have specific influence on SSD, such as the FOXP2 gene. Fisher, Vargha-Khadem, Watkins, Monaco, and Pembrey (1998) performed a genomewide linkage study on a family from the UK known as the K.E. family and identified a region on chromosome 7 that appeared to co-segregate with SSD and identified the causative gene as a brain-expressed transcription factor called FOXP2. Affected individuals have difficulty imitating mouth and face movements (orofacial apraxia), which is posited by the authors to be the core deficit in this family. The affected individuals show bilateral atrophy of the caudate nucleus. The caudate nucleus is part of the basal ganglia, which has well described associations with motor control.

Advances in genetic studies rely on well described phenotypes and endophenotypes for SSD. Clinically validated subtypes as well as theoretical models and genetic findings support the overlap of SSD, LI, and RD. An empirical approach to subtyping, such as factor analysis, may lend further support for both the unique and shared processes of these disorders.

\subsection{Empirical approach to subtyping of SSD}

The above clinical schemas for subtyping SSD have aided in predicting academic outcomes for children with SSD, assisted in the understanding of the shared and unshared 
processes of SSD, LI, and RD, and generated hypotheses regarding possible etiological bases for SSD. To our knowledge, however, no study has attempted to classify children with SSD empirically, using factor analysis to examine distinct dimensions of articulation, phonological processing, language, and oral motor skills. The major advantage of this approach is that it provides a data-driven method for investigating separable dimensions of speech/language abilities and disabilities. Further advantages of this method include its potential to reveal information about the different constructs that are measured by batteries of speech/language tests and ways to reduce large numbers of test scores to a smaller set of meaningful test composites. Distinct speech/language constructs, if validated in relation to clinical and biological correlates of SSD, could then be used to classify children into meaningful subtypes, or at least to recognize different phenotypic variations.

A recent study employed factor analysis to identify twins with LI (Viding et al., 2004). A principal component factor analysis conducted on eight language measures administered to 4-year-old twins yielded a single factor. Children were identified as language impaired if their score on this factor fell 1.10 standard deviations below the sample mean. Because the test battery used in this study did not encompass measures of speech production, investigation of the potentially distinct dimensions of speech and language skills was not possible.

The major aim of the present study was to investigate the factor structure of a comprehensive battery of measures administered to a large sample of children with early SSD. To determine the validity of the factors, we examined their relation to children's later reading and spelling skills, the persistence of SSD, and rates of affection status for speech, language, and reading disorders in biological relatives. Based on previous support for the utility of subtypes that distinguish isolated SSD from SSD plus LI (Lewis et al., 2000), we hypothesized that factor analysis would indicate that measures of speech sound skills will load on a separate factor from measures of language abilities. We further hypothesized that distinct speech and language constructs would be supported by their independent associations with reading and spelling skills, persistence of SSD, and family history of speech/language and reading disorders. In view of previous research showing differential associations of speech and language skills with reading and spelling (Lewis et al., 2002), we anticipated that speech sound abilities would be associated primarily with spelling, whereas language skills would be associated with both reading and spelling. We also anticipated that more severe SSD in early childhood would predict the persistence of SSD into the school-age years. Finally, based on genetic studies, we anticipate that both speech and language skills would predict affection status for speech, language, and reading disorders among biological relatives of the children with SSD.

\section{Method}

\subsection{Participants}

Participants were 185 children who were identified as having SSD at 3-7 years of age from the clinical caseloads of speech/language pathologists working at community speech 
and hearing centers or in private practice in the greater Cleveland area. All participants were screened to insure that they met the following criteria: (1) moderate to severe expressive speech sound impairment as defined by a score at or below the 10th percentile on the Goldman-Fristoe Test of Articulation Sounds in Words subtest (Goldman \& Fristoe, 1986), commission of at least three phonological processing error types as identified by the Khan-Lewis Phonological Analysis (KLPA; Khan \& Lewis, 1986), and a severity of involvement score of $<90 \%$ of consonants correct (PCC) based on a conversational speech sample (Shriberg et al., 1997); (2) normal hearing acuity as defined by passing a pure tone audiometric screening test at $25 \mathrm{dBHL}$ ISO for 500, 1000, 2000 , and $4000 \mathrm{~Hz}$ bilaterally and fewer than six reported episodes of otitis media prior to age 3 years as reported by the parent; (3) normal peripheral speech mechanism as documented on the Oral and Speech Motor Control Protocol (Robbins \& Klee, 1987); (4) absence of a history of neurological disorders or developmental delays other than speech and language as reported by the parent; (5) normal intelligence defined as a Performance IQ of 80 or above on the Wechsler Intelligence Scale for Children-Third Edition (WISC-III; Wechsler, 1991) or the Wechsler Preschool and Primary Scale of Intelligence-Revised (WPPSI-R; Wechsler, 1989). Table 1 summarizes the demographic and intelligence characteristics of the sample at preschool age and the subsample retested at school age.

\subsection{Procedures}

The participants were tested individually in two sessions to reduce potential effects of fatigue on test results. Testing was carried out in a speech research laboratory in the Department of Pediatrics at Case Western Reserve University or, at the parent's request, in a quiet and adequately lit room in the family's home. Speech productions were recorded on high-quality audiocassette tapes using a Sony Professional Tape Recorder (WM-DC6) and an Audio-Technica Omnidirectional Microphone (AT-804). Responses were recorded initially on-line using broad phonetic transcription. Speech sound samples were later transcribed as described below. All tests were presented in a counter balanced manner, with the more time consuming measures alternating with less lengthy measures. Thirty-eight participants were followed to school age and assessed for reading and spelling skills.

Table 1

Subject demographics at early childhood and school age

\begin{tabular}{llc}
\hline Demographic & Early childhood, & School age, \\
& mean (S.D.), & mean (S.D.), \\
& $N=185$ & $N 8$ \\
\hline Age (years) & $5.2(1.0)$ & $9.1(1.5)$ \\
SES & $3.84(1.1)$ & $3.7(1.2)$ \\
WPPSI-R/WISC-III Performance IQ & $97.7(13.7)$ & $108.6(15.9)$ \\
Males/females & $127 / 58$ & $26 / 12$ \\
\hline
\end{tabular}

Note: SES—socioeconomic status based on the Hollingshead Four Factor Index (Hollingshead, 1975). WISC-III: Wechsler Intelligence Scale for Children-Third Edition. 


\subsection{Early childhood measures (see Table 2)}

\subsubsection{Articulation}

The GFTA-Sounds in Words Subtest was administered to assess speech sound production in singletons and clusters in initial, medial, and final word positions. Responses were transcribed on-line as well as audiotape recorded for later review. Transcriptions of $10 \%$ of the total number of samples by a second speech-language pathologist yielded $95 \%$ point-to-point interjudge agreement. KLPA analyses were completed for responses to the GFTA. Findings from the KLPA used in the factor analysis included the age-adjusted percentile score and presence or absence of nondevelopmental phonological processes and syllable errors.

A conversational speech sample of at least 50 utterances was obtained using technical and interlocutor procedures for free speech sampling described in Shriberg and Kwiatkowski (1985). Speech sound development was further quantified based on the conversational sample. The Percentage of Consonants Correct (PCC), including subscale scores on the Late 8 consonants (Shriberg et al., 1997), was calculated, as well as Percentage of Consonants Correct-Revised (PCC-R) scores, in which consonant distortions are scored as correct (these are included in Table 3). Independent rescoring of approximately $10-15 \%$ of the speech samples obtained for this project yielded average point-to-point interjudge agreement values of $91 \%$ for broad transcription of consonants.

Table 2

Tests administered at the initial early childhood assessment and at the school-age follow-up

\begin{tabular}{|c|c|}
\hline $\begin{array}{l}\text { Articulation measures } \\
\text { Goldman-Fristoe Test of Articulation (GFTA) })^{\mathrm{a}, \mathrm{b}}\end{array}$ & $\begin{array}{l}\text { Semantic/syntactic measures } \\
\text { Test of Language Development- } \\
\text { Primary } 2 \text { (TOLDP: } 2 \text { or TOLDP:3) }\end{array}$ \\
\hline Khan-Lewis Phonological Analysis (KLPA) ${ }^{\mathrm{a}}$ & $\begin{array}{l}\text { Clinical Evaluation of Language } \\
\text { Fundamentals }-3(\mathrm{CELF} 3)^{\mathrm{b}}\end{array}$ \\
\hline Conversational speech sample $(\mathrm{PCC})^{\mathrm{a}, \mathrm{b}}$ & \\
\hline $\begin{array}{l}\text { Oral motor measures } \\
\text { Oral and Speech Motor Control Protocol }{ }^{\mathrm{a}} \\
\text { Fletcher Time-by-Count }{ }^{\mathrm{b}}\end{array}$ & \\
\hline $\begin{array}{l}\text { Phonological production measures } \\
\text { Nonsense Word Repetition Test (NWR) } \\
\text { Multisyllabic Word Repetition } \\
\text { Task (MWR) }\end{array}$ & $\begin{array}{l}\text { Written language measures } \\
\text { WRMT: Word ID and Word Attack } \\
\text { WIAT-Reading Comprehension }\end{array}$ \\
\hline Speech Error Phrases & Test of Written Spelling_-Third Edition (TWS3) ${ }^{\mathrm{b}}$ \\
\hline $\begin{array}{l}\text { Nonverbal intelligence } \\
\text { Performance subtests of the } \\
\text { WPPSI-R or WISC-III }{ }^{\mathrm{a}, \mathrm{b}}\end{array}$ & $\begin{array}{l}\text { Genetic } \\
\text { Family History Questionnaire }\end{array}$ \\
\hline
\end{tabular}

Note: WRMT, Woodcock Reading Mastery Tests; WIAT, Wechsler Individual Achievement Test; WPPSI-R, Wechsler Preschool and Primary Scale of Intelligence-Revised; WISC-III, Wechsler Intelligence Scale for Children-Third Edition.

a Administered at preschool (4-7 years).

b Administered at school age (7-12 years). 
Table 3

Factor loadings of early childhood speech and language measures in two-factor solution after varimax rotation

\begin{tabular}{lll}
\hline Measure & $\begin{array}{l}\text { Articulation/phonology } \\
\text { factor }\end{array}$ & $\begin{array}{l}\text { Semantic/syntactic } \\
\text { factor }\end{array}$ \\
\hline GFTA & $\mathbf{0 . 7 8 6}$ & 0.145 \\
Multisyllabic Word Repetition & $\mathbf{0 . 7 5 2}$ & 0.311 \\
Late 8 Sound PCC & $\mathbf{0 . 7 1 5}$ & 0.125 \\
Nonsense Word Repetition & $\mathbf{0 . 6 9 7}$ & 0.243 \\
PCC-R & $\mathbf{0 . 6 6 5}$ & 0.190 \\
Speech Error Phrase Repetition & $\mathbf{0 . 6 0 4}$ & 0.178 \\
Sentence Imitation & 0.225 & $\mathbf{0 . 7 2 9}$ \\
Oral Vocabulary & 0.102 & $\mathbf{0 . 7 7 6}$ \\
Grammatical Understanding & 0.207 & $\mathbf{0 . 6 7 1}$ \\
Grammatical Completion & 0.320 & $\mathbf{0 . 6 3 5}$ \\
Picture Vocabulary & 0.102 & $\mathbf{0 . 4 7 9}$
\end{tabular}

Note: GFTA-Goldman-Fristoe Test of Articulation. PCC: percent of consonants correct. PCC-R: percent of consonants correct-revised. Bold values indicate the highest loadings associated with each factor. $N=185$.

\subsubsection{Phonological production}

The Multisyllabic Word Repetition Task (MWR; Catts, 1986), Nonsense Word Repetition Test (NWR; Kamhi \& Catts, 1986), and Speech Error Phrases Test (Catts, 1986) were administered to assess accuracy of phoneme production in multisyllabic real and nonsense words. On these tasks, participants were asked to repeat 20 real and nonsense multisyllabic words or phrases presented by audiotape. The responses were audiotaped, phonetically transcribed, and analyzed for phonological processes and syllable structure. The percent of phonemes correctly produced was entered into the data analysis.

\subsubsection{Oral motor skills}

The Oral and Speech Motor Control Protocol (Robbins \& Klee, 1987) assessed oral structures and motor functions. Based on observations of the child's oral structures at rest and during repetition of syllables, words, and phrases, this protocol yields a Total Function score (TFS) and a Total Structure score (TSS). This test also assessed diadochokinetic rates. Z-scores were obtained to adjust for gender and age using the data provided by Robbins and Klee (1987).

\subsubsection{Lexical and grammatical skills}

To assess a broad range of language abilities, the children were administered the Picture Vocabulary, Relational Vocabulary, Oral Vocabulary, Grammatical Understanding, Sentence Imitation, and Grammatical Completion subtests of the Test of Language Development_Primary Second Edition (TOLD-P:2; Newcomer \& Hammill, 1988) or the Test of Language Development-Primary Third Edition (TOLD-P:3; Newcomer and Hammill, 1997).

\subsubsection{Nonverbal $I Q$}

Nonverbal IQ was assessed with either the WPPSI-R or the WISC-III. The WISC-III Performance subtests administered included Picture Completion, Coding, Picture 
Arrangement, Block Design, and Object Assembly. The WPPSI-R subtests included Object Assembly, Geometric Design, Block Design, Mazes, Picture Completion, and Animal Pegs.

\subsection{School-age measures (see Table 2)}

\subsubsection{Articulation and phonological processing measures}

Measures administered at early childhood were re-administered at follow-up. These included the GFTA and a conversational speech sample from which the PCC and Late 8 consonants were calculated.

\subsubsection{Lexical and grammatical skills}

The TOLD-P:3 or the Clinical Evaluation of Language Fundamentals-Third Edition (CELF-3; Semel, Wiig, \& Secord, 1995) was re-administered at school age to assess lexical and grammatical skills.

\subsubsection{Reading decoding}

The Word Attack and Word Identification subtests of the Woodcock Reading Mastery Tests-Revised (WRMT-R; Woodcock, 1987) were administered to assess participants' reading decoding skills.

\subsubsection{Reading Comprehension}

The Reading Comprehension subtest of the Wechsler Individual Achievement Test (WIAT; Wechsler, 1992) was also administered to evaluate participants' ability to read short passages and answer questions in context.

\subsubsection{Spelling}

Written spelling was evaluated using the Test of Written Spelling-Third Edition (TWS3; Larsen \& Hammill, 1994). The TWS-3 contains both predictable and unpredictable words. Predictable words are those that are spelled as they sound, whereas unpredictable words are exceptions to more regular spelling to sound correspondences. Examples of predictable words are "stop, forty, visualize, and ambiguous". Examples of unpredictable words are "two, eight, facsimile, and feign".

\subsection{Persistent versus recovered SSD}

Children were classified into persistent versus recovered groups based on school-age scores on the GFTA and PCC. The recovered group $(n=15)$ consisted of children who made no errors on the GFTA, all scored at the 99 percentile, and had PCC scores above $96 \%$ based on the conversational speech sample. Children in the persistent group $(n=13)$ had at least three errors on the GFTA and scored below $96 \%$ on the PCC metric. All children in the persistent group scored below the 65 percentile on the GFTA $(M=30.1$; S.D. $=21.8)$. Children who met criteria for recovery on only one of the two measures $(n=10)$ were excluded from the outcome analysis. 


\subsection{Affection status of family members}

Affection status of nuclear family members was determined both through historical report and by directly testing family members when possible. Affection status for siblings under 3 years of age was not determined. Following the procedures described by Lewis and Freebairn (1993), parents were interviewed for family history of speech and language disorders. Family members were classified as affected for a SSD and/or language impairment if they had ever been enrolled in therapy for SSD and/or LI. The informant was also questioned about whether or not family members had a history of reading difficulties. Reliable information on the specific type of speech and language problem could not always be obtained from the informants. Efforts were made to secure school records but detailed therapy records were not always available. Thus, affection status was obtained by retrospective methods, with reliance on self-reports and descriptions by family members. Determination of affection status in this way is a standard procedure in studies of family pedigrees, and broadly classifies family members as affected or generally unaffected based on report of one or both caregivers. It also allows for the identification of family members as affected whose speech sound and language problems may have resolved by the test date.

Further phenotyping of nuclear family members was accomplished by direct testing of siblings who were 4 years of age or older and all parents who agreed to testing. Siblings who were 4-7 years of age were classified as positive for SSD if they met the same criteria described above for the probands. Older siblings and parents were considered to have speech sound difficulties if they were able to repeat less than $75 \%$ of the multisyllabic or nonsense words correctly (i.e. words containing one or more speech errors other than distortions). Siblings and parents were considered to have a LI if they scored 1S.D. or greater below the mean on two or more subscales of the TOLD-P:2 or TOLD-P:3 or the CELF-3. Family members were considered affected if they met these criteria or reported a history of speech/language therapy.

\subsection{Analysis}

Principal axis factor analysis with varimax rotation was conducted with age standardized scores for measures listed in Table 3. To identify distinct factors, tests with low primary loadings or high cross loadings were excluded after the initial analysis. Factor scores were defined based on factor weightings.

Associations between factor scores and reading and spelling measures were examined by correlation. Independent $t$-tests were employed to compare children with persistent versus recovered SSD on the two factors. With the present sample size, power was only sufficient to detect large effect sizes (e.g. power was at $80 \%$ at $p<0.05$ to detect effect sizes in standard deviation units of about 1).

To investigate associations of factor scores with affection status for speech, language, and reading disorders in family members, we used a technique modeled after Wijsman et al. (2004). In brief, logistic regression was employed to examine the factor scores as predictors of affection status. Because affection status, if genetically based, would vary with the degree of relationship to the proband with SSD, a kinship coefficient was included 
in the logistic models to adjust for this factor. The kinship coefficient term was defined as $2^{-(k+1)}$, where $k$ is the degree of relationship (e.g. first degree for parents and siblings and second degree for half-siblings and grandparents). Males are known to be at greater risk for these disorders than females (Shriberg et al., 1998; Tomblin et al., 1997); hence, gender was also included in the models. The final models took the form:

$$
y_{j f}=\mu+\alpha x_{i f}+\gamma y_{i f}+\beta \Phi_{j f}+\delta z_{j f}+e_{j f},
$$

where $y_{j f}$ is the affection status (for speech, language, or reading impairment) for relative $j$ in family $f, x_{i f}$ and $y_{i f}$ the two hypothesized factor scores for the proband in family $f, \Phi_{j f}$ the kinship coefficient between individual $j$ (the relative in question) and the proband in family $f, z_{j f}$ the gender of relative $j$ in family $f$, and $e_{j f}$ is the residual error term for relative $j$ in family $f$. The partial-regression coefficients $\alpha, \gamma$, and $\beta$ test for the associations between the proband's factor scores (coefficients $\alpha$ and $\gamma$ ) and affection status (coefficient $\beta$ ) in the relative, controlling for degree of kinship between the proband and the relative and gender of the relative. Two-way interaction terms were fitted as well, but did not attain statistical significance and were thus excluded from further consideration. To insure that the results of the logistic regressions were not confounded by correlations between individuals within pedigrees, these analyses were repeated using SEGREG from the program package S.A.G.E. (Version 4.5, 2003). The advantage of this program is that it accounts for familial correlations within a segregation analysis framework. In these analyses, the kinship coefficient, gender, and proband factor scores were entered as predictors of susceptibility to each of the disorders. Because the logistic regression and the segregation analyses yielded similar findings, only the results from logistic regression are presented below.

\section{Results}

\subsection{Factor analyses}

Factor analysis yielded a two-factor solution accounting for $56.6 \%$ of the variance in scores. The first factor, termed articulation/phonology, had an eigenvalue of 3.86 and explained $48.2 \%$ of the variance. The second factor, termed syntactic/semantic, had an eigenvalue of 1.52 and explained $19 \%$ of the variance. Loadings for all measures are presented in Table 3.

\subsection{Prediction of school-age reading and spelling and persistence of SSD}

As indicated in the correlational analysis (see Table 4), the articulation/phonology factor was more strongly correlated with the spelling measure (TWS-3) than the semantic/ syntactic factor. The semantic/syntactic factor was more strongly correlated with the Word Attack subtest and the Reading Comprehension subtest than the articulation/phonology factors. Both factors demonstrated similar correlations with the Word Identification subtest. Independent $t$-tests were employed to compare children with persistent SSD $(n=15)$ and children with recovered SSD $(n=13)$ on the factor scores. The mean factor 
Table 4

Correlation of early childhood factors to reading and spelling measures at school age $(N=185)$

\begin{tabular}{lll}
\hline Measure & $\begin{array}{l}\text { Articulation/phonology } \\
\text { factor }\end{array}$ & $\begin{array}{l}\text { Semantic/syntactic } \\
\text { factor }\end{array}$ \\
\hline Spelling & $0.417^{* * *}$ & $0.323^{*}$ \\
Word Attack & $0.454^{* *}$ & $0.582^{* *}$ \\
Word Identification & $0.604^{* *}$ & $0.621^{* *}$ \\
Reading Comprehension & $0.542^{* *}$ & $0.732^{* *}$ \\
\hline
\end{tabular}

${ }^{*} p<0.05$.

*** $p<0.001$.

scores for children in the persistent group were as follows: articulation/phonology factor $M=-1.66$, S.D. $=0.47$; semantic/syntactic factor $M=-0.65$, S.D. $=0.93$. The mean factor scores for children in the recovered group were: articulation/phonology factor $M=-0.74$, S.D. $=0.69 ;$ semantic/syntactic factor $M=-0.29$, S.D. $=0.81$. The groups differed on the articulation/phonology factor $(t=-4.26 ; p \leq 0.001)$ but not the semantic/ syntactic factor $(t=-1.07 ; p=0.296)$. Specifically, higher scores on the articulation/ phonology factor were associated with greater rates of recovered SSD (see Appendix A for a summary of school-age performance on follow-up measures).

\subsection{Prediction of affection status of family members}

Table 5 presents results from analysis of predictors of affection status in nuclear family members of the probands. The kinship coefficient predicted affection status for SSD $(p<0.0005)$, LI $(p<0.0005)$, and RD $(p<0.0005)$. In each case, the odds of a disorder among nuclear family members were higher the closer the degree of kinship. The gender of the relative was also associated with affection status for speech $(p<0.0005)$, language $(p<0.0005)$, and reading $(p<0.002)$. In each instance, male gender predicted higher probability of these disorders among family members. Even with kinship and gender taken into account, lower proband scores on the articulation/ phonology factor were associated with higher odds for SSD $(p=0.026), \operatorname{LI}(p=0.024)$, and $\operatorname{RD}(p=0.0005)$, whereas lower proband scores on the semantic/syntactic factor predicted higher odds for LI ( $p=0.040)$ but not SSD $(p=0.902)$ or $\operatorname{RD}(p=0.132)$. The findings thus indicate that the proband's scores on the two factors were related to the susceptibility of their relatives to disorders of oral and written language.

Table 5

The relationship of factor scores to familial risk for SSD, LI, and RD as explained by $p$-values using logistic regression $(N=185)$

\begin{tabular}{lllll}
\hline Disorders & $\begin{array}{l}\text { Kinship } \\
\text { coefficient }\end{array}$ & Sex & $\begin{array}{l}\text { Articulation/phonology } \\
\text { factor }\end{array}$ & $\begin{array}{l}\text { Semantic/syntactic } \\
\text { factor }\end{array}$ \\
\hline Affection for SSD & $<0.0005$ & $<0.0005$ & 0.026 & 0.902 \\
Affection for LI & $<0.0005$ & $<0.0005$ & 0.024 & 0.040 \\
Affection for RD & $<0.0005$ & $<0.002$ & $<0.0005$ & 0.132 \\
\hline
\end{tabular}

Note: SSD—speech sound disorder; LI-language impairment; RD—reading disorder. 


\section{Discussion}

Few studies have employed factor analysis in the classification of children with speech and language impairments. The present study examined factors related to SSD and their usefulness in classification of SSD, familial aggregation of SSD, and prediction of longterm outcomes of children with early SSD. Consistent with our hypothesis, factor analyses indicated the independence of articulation/phonology versus semantic/syntactic disorder in early childhood SSD. The common loadings of measures of articulation and phonology on a single factor suggest that these deficits co-occur, at least during early childhood. Colledge et al. (2002) reported that the GFTA and a nonword repetition task were highly correlated in a cohort of 4-year-old children and shared $62 \%$ of the reliable variance. The repetition of nonsense words is commonly thought of as a task assessing working phonological memory rather than speech production skills. However, for young children such a task also taxes their articulation abilities. Later on, as the child acquires written language, phonological processing skills become better developed and the articulatory components of speech sound acquisition are mastered. Additional factors, such as one reflecting measures of phonological processing, may thus emerge in older children.

Further support for the validity of the factor structure was provided by the association of proband factor scores with affection status of family members. Even with the degree of kinship and gender of the relative taken into account, the articulation/phonology factor predicted relatives' affection status for speech, language, and reading. In contrast, the semantic/syntactic factor predicted only family members' affection status for LI. Previous research has indicated that language, but not speech, skills predicts later literacy (Bishop \& Adams, 1990; Catts, 1993; Magnusson \& Naucler, 1990; Nathan et al., 2004). Our findings suggest that the articulation/phonology factor predicts deficits in reading in other family members within a pedigree. These findings are also consistent with our previous report of co-morbid aggregation of phenotypes within a pedigree and support a general verbal trait deficit model of SSD, with many genes contributing in concert to phenotypic variations. Individuals within a single family may demonstrate a variety of disorders depending on the specific combination of risk genes that they inherit and the shared and unshared environmental effects to which they are exposed.

As also hypothesized, follow-up of a subgroup of children to school age confirmed the association of these factors with later reading and spelling skills and the persistence or recovery of the SSD. The articulation/phonology factor correlated with nonword decoding and spelling, two skills that have been shown to relate to phonological awareness and phonological processing (Lewis et al., 2002); and the semantic/syntactic factor correlated with reading decoding and reading comprehension scores. These results are in agreement with previous studies showing that early phonological processing skills are closely related to spelling and reading decoding, whereas other language skills are better predictors of reading comprehension (Lewis et al., 2002). They also support the findings of Pennington and colleagues (Pennington \& Lefly, 2001; Raitano, Pennington, Tunick, Boada, \& Shriberg, 2004; Tunick \& Pennington, 2002,) that early developmental problems in spoken language predict later reading abilities in high-risk families. Associations of each of the factors with real word reading suggest that both skills are important for reading acquisition. 
The articulation/phonology factor was also related to persistent SSD, a finding that is relevant to recent reports that children with persistent communicative disorders are more likely to have later academic difficulties, especially with written language (Bishop, Price, Dale, \& Plomin, 2003; Nathan et al., 2004; Stothard et al., 1998). This finding supports the hypothesis of Raitano et al. (2004) that children with persistent speech sound production errors have poorer underlying phonological representations than children whose SSD resolves by 6 years of age, and are thus at greater risk for reading difficulties than children with transient SSD.

In another study of differences between children with persistent versus transient SSD, Stothard et al. (1998) followed 71 children with speech and language impairment who were initially seen at age 4 years. At 5 years 6 months children were classified into those whose language problem had resolved and those whose problem persisted. At 15-16 years of age, children whose problems had resolved did not differ from controls on vocabulary and language comprehension measures, but did differ on tests of phonological processing and literacy skills. Children with unresolved problems at 5 years 6 months of age continued to have problems in both spoken and written language at 15-16 years. Further evidence for a distinction between persistent and transient speech and language disorders is provided by Bishop et al. (2003). The latter investigators found higher heritability for SSD in children with more persistent disorders, suggesting a unique etiological basis.

Several limitations of the present study should be noted. First, receptive phonological processing skills were not assessed. We do not know if receptive phonological skills are a component of the articulation/phonology factor or a third unique factor. A second limitation is the small number of children who were followed into school age. We are currently following a larger cohort of children to assess if the factor structure remains the same or changes with the acquisition of literacy skills. A final limitation is the measures that are available to assess phonological processing skills. Some measures assess more than a single component of articulation/phonology. For example, repetition of nonwords assesses both phonological memory and articulatory ability.

In conclusion, this study demonstrated that an empirical approach, factor analysis, identifies different dimensions of SSD at early childhood, and that these dimensions, in turn, are useful in predicting affection status of family members, school-age outcomes, and the persistence of SSD. Our findings support two distinct constructs of early childhood SSD_articulation/phonology deficits and semantic/syntactic deficits, each with different implications for academic development. These findings validate our previous studies that have found differences in school-age outcomes when children with early SSD are subgrouped based on the presence or absence of additional language deficits (Lewis et al., 2000). Because both persistent SSD and early language deficits have implications for later academic achievement, evaluation of both of these abilities may enhance efforts to identify and treat early-emerging learning problems. Development of speech sound skills may be particularly critical in spelling acquisition. The association of the two factors with the affection status of family members of the probands also suggests that assessment of these skills may be useful in defining phenotypes for genetic studies of speech and language disorders. The use of empirically validated test constructs based on multiple measures offers a viable alternative to less reliable historical reports or to disabilities defined in terms of single-measure cut-off scores. 


\section{Acknowledgements}

This research was supported by the National Institutes of Health, National Institute on Deafness and Other Communication Disorders, Grant DC00528 and NIH-NIDCD 1 RO3 DC004005, Barbara A. Lewis, Principal Investigator. We wish to express our appreciation to the speech/language pathologists who assisted us in recruiting subjects, and to the families who generously agreed to participate.

Some of the analyses were performed using the program package S.A.G.E., release 4.5, which is supported by the U.S. Public Health Resource Grant RR03655 from the National Center for Research Resources.

\section{Appendix A. School-age performance on follow-up reading and spelling measures (means and standard deviations)}

\begin{tabular}{llllrr}
\hline Measure & $\begin{array}{l}\text { Persistent SSD, } \\
\text { mean (S.D.), } \\
N=15\end{array}$ & $\begin{array}{l}\text { Recovered SSD, } \\
\text { mean (S.D.), } \\
N=13\end{array}$ & $\begin{array}{l}\text { Total sample, } \\
\text { mean (S.D.), } \\
N=28\end{array}$ & $F$-value & $p$-Value \\
& $79.4(9.7)$ & $94.1(15.4)$ & $86.3(13.7)$ & 6.8 & 0.015 \\
Test of Written Spelling & $87.9(16.4)$ & $101.2(18.6)$ & $93.8(17.8)$ & 3.2 & 0.084 \\
Word Attack & $93.7(12.8)$ & $99.3(13.8)$ & $95.8(17.0)$ & 1.0 & 0.330 \\
Word Identification & $94.9(11.5)$ & $101.9(12.9)$ & $99.0(15.0)$ & 2.7 & 0.117 \\
Reading Comprehension & $91.6(4.6)$ & $97.7(1.1)$ & $94.8(4.1)$ & 22.7 & $<0.0001$ \\
Percent Consonant Correct & $30.1(21.8)$ & $99.0(0.0)$ & $64.2(37.5)$ & 149.6 & $<0.0001$ \\
Goldman-Fristoe Test of Articulation & & & & &
\end{tabular}

\section{A.1. Continuing education}

Dimensions of early speech sound disorders: a factor analytic study

Self-study questions:

1. Schemas for subtyping children with speech sound disorders have been based on:
a. The presence or absence of additional language impairments.
b. Type of speech sound errors observed.
c. Accompanying medical conditions.
d. All of the above.
e. None of the above.

2. The major advantage to a factor analytic approach to subtyping is:
a. It distinguishes between speech and language disorders.
b. It takes into account etiological differences.
c. It examines different types of speech errors.
d. It is data driven.
e. It differentiates speech delay from speech disorders.

3. The findings from this study support a familial basis for speech sound disorders because:

a. The child's scores on the two factors were related to the susceptibility of their relatives to disorders of speech and language.

b. Larger families had more affected family members. 
c. Sisters were more often affected than brothers.

d. Children had a mother or father with a history of a speech or language disorder.

e. None of the above.

4. The findings of this study supported the association of early childhood speech and language disorders to later reading problems because:

a. Children with persistent disorders had more reading problems.

b. The preschool factor scores predicted later reading problems.

c. Family members reported a high rate of reading problems.

d. None of the above.

e. A and B.

5. The findings of this study suggest that when evaluating a child SLPs should:
a. Inquire about family history.
b. Use cut-off scores based on single measures.
c. Use empirically validated test constructs based on multiple measures.
d. Consider biological factors.
e. Consider environmental factors.

\section{References}

Aram, D., \& Hall, N. (1989). Longitudinal follow-up of children with preschool communication disorders: Treatment implications. School Psychology Review, 18, 487-501.

Bishop, D., \& Adams, C. (1990). A prospective study of the relationship between specific language impairment, phonological disorders and reading retardation. Journal of Child Psychology and Psychiatry, 31, 1027-1057.

Bishop, D., North, T., \& Donlan, C. (1995). Genetic basis of specific language impairment: Evidence from a twin study. Developmental Medicine and Child Neurology, 37, 56-71.

Bishop, D., Price, T., Dale, P., \& Plomin, R. (2003). Outcomes of early language delay: II. Etiology of transient and persistent language difficulties. Journal of Speech, Language, and Hearing Research, 46, 561-575.

Caplan, D. (1992). Language: Structure, processing, and disorders. Cambridge, MA: MIT Press.

Caplan, D. (1994). Language and the brain. Handbook of psycholinguistics, New York, NY: Academic Press Inc.

Carrow-Woolfolk, E., \& Lynch, J. I. (1982). An integrative approach to language disorders in children. New York, NY: Grune \& Stratton, Inc.

Catts, H. (1986). Speech production/phonological deficits in reading disordered children. Journal of Learning Disabilities, 19, 504-508.

Catts, H. (1993). The relationship between speech-language impairments and reading disabilities. Journal of Speech and Hearing Research, 36, 948-958.

Catts, H. W., \& Kamhi, A. G. (1986). The linguistic basis of reading disorders: Implications for the speechlanguage pathologist. Language, Speech and Hearing Services in the Schools, 17, 31.

Colledge, E., Bishop, D., Koeppen-Schomerus, G., Price, T., Happe, F., Eley, T., et al. (2002). The structure of language abilities at 4 years: A twin study. Developmental Psychology, 38, 749-757.

Dodd, B. (1995). Differential diagnosis \& treatment of children with speech disorder. London: Whurr Publishers Ltd.

Felsenfeld, S., McGue, M., \& Broen, P. (1995). Familial aggregation of phonological disorders: Results from a 28year follow-up. Journal of Speech and Hearing Research, 38, 1091-1107.

Felsenfeld, S., \& Plomin, R. (1997). Epidemiological and offspring analyses of developmental speech disorders using data from the Colorado Adoption Project. Journal of Speech and Hearing Research, 40, 778-791.

Fisher, S. E., Vargha-Khadem, F., Watkins, K. E., Monaco, A. P., \& Pembrey, M. E. (1998). Localisation of a gene implicated in a severe speech and language disorder. Nature Genetics, 18, 168-170.

Gathercole, S. E., \& Baddeley, A. D. (1989). Evaluation of the role of phonological STM in the development of vocabulary in children: A longitudinal study. Journal of Memory and Language, 28, 200-213. 
Goldman, R., \& Fristoe, M. (1986). The Goldman-Fristoe Test of Articulation (GFTA). Circle Pines, MN: American Guidance Service, Inc.

Gopnik, M., \& Crago, M. (1991). Familial aggregation of a developmental language disorder. Cognition, 39, 1-50.

Hall, P., \& Tomblin, J. (1978). A follow-up study of children with articulation and language disorders. Journal of Speech and Hearing Disorders, 43, 227-241.

Hollingshead, A. B. (1975). Four factor index of social class. Unpublished manuscript (available from Hollingshead, A. B. New Haven, CT 06520: Department of Sociology, Yale University).

Kamhi, A., \& Catts, H. (1986). Toward an understanding of developmental language and reading disorders. Journal of Speech and Hearing Disorders, 51, 337-347.

Kandel, E. R., Schwartz, J. H., \& Jessel, T. M. (1991). Principles of neural science. New York, NY: Science Publishing Inc.

Khan, L., \& Lewis, N. (1986). Khan-Lewis phonological analysis (KLPA). Circle Pines, MN: American Guidance Service.

Lahey, M., \& Edwards, J. (1995). Specific language impairment: Preliminary investigation of factors associated with family history and patterns of language performance. Journal of Speech and Hearing Research, 38, 657683.

Larsen, S., \& Hammill, D. (1994). Test of Written Spelling-Third edition (TWS-3). San Antonio, TX: The Psychological Corporation.

Lewis, B. (1992). Pedigree analysis of children with phonology disorders. Journal of Learning Disabilities, 25, 586-597.

Lewis, B., \& Freebairn, L. (1993). A clinical tool for evaluating the familial basis of speech and language disorders. American Journal of Speech and Language Pathology, 2, 38-43.

Lewis, B., \& Freebairn, L. (1998). Speech production skills of nuclear family members of children with phonology disorders. Speech and Language, 41, 45-61.

Lewis, B., Freebairn, L., \& Taylor, H. (2000). Follow-up of children with early expressive phonology disorders. Journal of Learning Disabilities, 33, 433-444.

Lewis, B., Freebairn, L., \& Taylor, H. (2002). Correlates of spelling abilities in children with early speech sound disorders. Reading and Writing: An Interdisciplinary Journal, 15, 389-407.

Lewis, B., O’Donnell, B., Freebairn, L., \& Taylor, H. (1998). Spoken language and written expression-Interplays of delays. American Journal of Speech-Language Pathology, 7, 66-73.

Lewis, B., \& Thompson, L. (1992). A study of developmental speech and language disorders in twins. Journal of Speech and Hearing Research, 35, 1086-1094.

Magnusson, E., \& Naucler, K. (1990). Reading and spelling in language disordered children-linguistic and metalinguistic prerequisites: Report on a longitudinal study. Clinical Linguistics and Phonetics, 4, 49-61.

Menyuk, P., Chesnick, M., Liebergott, J., Korngold, B., D’Agostino, R., \& Belanger, A. (1991). Predicting reading problems in at-risk children. Journal of Speech and Hearing Research, 34, 893-903.

Nathan, L., Stackhouse, J., Goulandris, N., \& Snowling, M. (2004). The development of early literacy skills among children with speech difficulties: A test of the "Critical Age Hypothesis". Journal of Speech, Language, and Hearing Research, 47, 377-391.

Neils, J., \& Aram, D. (1986). Family history of children with developmental language disorders. Perceptual and Motor Skills, 63, 655-658.

Newcomer, P., \& Hammill, D. (1988). Test of Language Development-Primary second edition TOLD:P-2. Austin, TX: PRO-ED.

Newcomer, P., \& Hammill, D. (1997). Test of Language Development_Primary third edition TOLD:P-3. Austin, TX: PRO-ED.

Pennington, B., \& Lefly, D. (2001). Early reading development in children at family risk for dyslexia. Child Development, 72, 816-833.

Plomin, R., \& Kovas, Y. (2005). Generalist genes and learning disabilities. Psychological Bulletin, 131(4), 592617.

Raitano, N., Pennington, B., Tunick, R., Boada, R., \& Shriberg, L. (2004). Preliteracy skills of subgroups of children with speech sound disorders. Journal of Child Psychology and Psychiatry, 45, 821-835.

Rice, M., Haney, K., \& Wexler, K. (1998). Family histories of children with SLI who show extended optional infinitives. Journal of Speech, Language, and Hearing Research, 41, 419-432. 
Robbins, J., \& Klee, T. (1987). Clinical assessment of oropharyngeal motor development in young children. Journal of Speech and Hearing Disorders, 52, 271-277.

S.A.G.E. 4.5 (2003). Statistical analysis for genetic epidemiology. http://darwin.cwru.edu/sage/.

Semel, E., Wiig, E., \& Secord, W. (1995). Clinical evaluation of language fundamentals-Third edition (CELF-3). San Antonio, TX: The Psychological Corporation.

Shriberg, L. (1993). Four new speech and prosody-voice measures for genetics research and other studies in developmental phonological disorders. Journal of Speech and Hearing Research, 36, 105-140.

Shriberg, L. (November 2002). Classification and misclassification of child speech sound disorders. Paper presented at the annual convention of the American Speech Language and Hearing Association.

Shriberg, L., \& Austin, D. (1998). Comorbidity of speech-language disorder: Implications for a phenotype marker for speech delay. In R. Paul (Ed.), Exploring the speech/language connection (pp. 73-118). Baltimore: Brookes.

Shriberg, L., Austin, D., Lewis, B., McSweeny, J., \& Wilson, D. (1997). The percentage of consonant correct (PCC) metric: Extensions and reliability data. Journal of Speech and Hearing Research, 40, 708-722.

Shriberg, L., \& Kwiatkowski, J. (1982). Phonological disorders I: A diagnostic classification system. Journal of Speech and Hearing Disorders, 47, 226-241.

Shriberg, L., \& Kwiatkowski, J. (1985). Continuous speech sampling for phonologic analyses of speech-delayed children. Journal of Speech and Hearing Disorders, 50, 323-334.

Shriberg, L., \& Kwiatkowski, J. (1994). Developmental phonological disorders I: A clinical profile. Journal of Speech and Hearing Research, 37, 1100-1126.

Shriberg, L., Lewis, B., Tomblin, J., McSweeny, J., Karlsson, H., \& Scheer, A. (2005). Toward diagnostic and phenotype markers for genetically-transmitted speech sound disorders. Journal of Speech, Language, and Hearing Research, 48, 834-852.

Shriberg, L., Tomblin, J., \& McSweeny, J. (1998). Prevalence of speech delay in 6-year-old children and comorbidity of language impairment. Journal of Speech, Language, and Hearing Research, 42, 14611481 .

Smith, S. D., Pennington, B. F., Boada, R., \& Shriberg, L. D. (2005). Linkage of speech sound disorder to reading disability loci. Journal of Child Psychology and Psychiatry, 46, 1057-1066.

Spitz, R., Tallal, R., Flax, J., \& Benasich, A. (1997). Look who's talking: A prospective study of familial transmission of language impairments. Journal of Speech and Hearing Research, 40, 990-1001.

Stein, C., Schick, J., Taylor, H., Shriberg, L., Millard, C., Kundtz-Kluge, A., et al. (2004). Pleiotropic effects of a chromosome 3 locus on speech sound disorder and reading. American Journal of Human Genetics, 74, 283 297.

Stothard, S., Snowling, M., Bishop, D., Chipchase, B., \& Kaplan, C. (1998). Language impaired preschoolers: A follow-up into adolescence. Journal of Speech, Language, and Hearing Research, 41, 407-418.

Tallal, P., Ross, P., \& Curtiss, S. (1989). Familial aggregation in specific language impairment. Journal of Speech and Hearing Research, 54, 167-173.

Tomblin, J. (1989). Familial concentration of developmental language impairment. Journal of Speech and Hearing Disorders, 54, 287-295.

Tomblin, J., \& Buckwalter, P. (1998). Heritability of poor language achievement among twins. Journal of Speech, Language, and Hearing Research, 41, 188-199.

Tomblin, J., Records, N., Buckwalter, P., Zhang, X., Smith, E., \& O’Brien, M. (1997). Prevalence of specific language impairment in kindergarten children. Journal of Speech, Language, and Hearing Research, 40, 1245-1260.

Tunick, R., \& Pennington, B. (2002). The etiological relationship between reading disability and phonological disorder. Annals of Dyslexia, 52, 75-95.

Viding, E., Spinath, F., Price, T., Bishop, D., Dale, P., \& Plomin, R. (2004). Genetic and environmental influence on language impairment in 4-year-old same sex and opposite-sex twins. Journal of Child Psychology and Psychiatry, 45, 315-325.

Wechsler, D. (1989). Wechsler Preschool and Primary Scale of Intelligence-Revised (WPPSI-R). San Antonio, TX: The Psychological Corporation.

Wechsler, D. (1991). Wechsler Intelligence Scale for Children-Third edition (WISC-III). San Antonio, TX: The Psychological Corporation. 
Wechsler, D. (1992). Wechsler Individual Achievement Test (WIAT). San Antonio, TX: The Psychological Corporation.

Wijsman, E., Robinson, N., Ainsworth, K., Rosenthal, E., Holzman, T., \& Raskind, W. (2004). Familial aggregation patterns in mathematical ability. Behavior Genetics, 34, 51-62.

Woodcock, R. (1987). Woodcock Reading Mastery Test_Revised. Circle Pines, MN: American Guidance Service, Inc.

Young, A., Beitchman, J., Johnson, C., Douglas, L., Atkinson, L., Escobar, M., et al. (2002). Young adult academic outcomes in a longitudinal sample of early identified language impaired and control children. Journal of Child Psychology and Psychiatry, 43, 635-645. 